\title{
The Frank Stinchfield Award
}

\section{The Impact of Socioeconomic Factors on Outcome After THA}

\author{
A Prospective, Randomized Study
}

\author{
R. Allen Butler MD, Seth Rosenzweig MD, \\ Leann Myers PhD, Robert L. Barrack MD
}

Published online: 18 August 2010

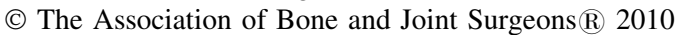

\begin{abstract}
Background Most studies of total hip arthroplasty (THA) focus on the effect of the type of implant on the clinical result. Relatively little data are available on the impact of the patient's preoperative status and socioeconomic factors on the clinical results following THA.

Questions/purposes We determined the relative importance of patient preoperative and socioeconomic status compared to implant and technique factors in predicting patient outcome as reflected by scores on commonly utilized rating scales (eg, Harris Hip Score, WOMAC, SF-12,
\end{abstract}

The institution of one or more of the authors has received funding from Smith \& Nephew, Inc, Memphis, TN (RAB, SR, RLB) and DePuy, Inc, Warsaw, IN (RAB, SR, RLB).

One or more of the authors certifies that he (RLB) has or may receive payments or benefits from a commercial entity related to this work. Each author certifies that his or her institution approved the human protocol for this investigation and that all investigations were conducted in conformity with ethical principles of research, and that informed consent for participation in the study was obtained.

This work was performed at Tulane University School of Medicine, New Orleans, LA.

R. Allen Butler

Starkville Orthopedic Clinic, Starkville, MS, USA

S. Rosenzweig

Dauterive Orthopaedics \& Sports Medicine, New Iberia, LA, USA

\section{Myers}

Department of Biostatistics, Tulane University School of Public

Health \& Tropical Medicine, New Orleans, LA, USA

\section{R. L. Barrack $(\bowtie)$}

Department of Orthopaedic Surgery, Washington University

School of Medicine, One Barnes-Jewish Hospital Plaza,

11300 West Pavilion, St Louis, MO 63110, USA

e-mail: barrackr@wustl.edu; pouchera@wustl.edu degree of patient satisfaction, or presence or severity of thigh pain) following cementless THA.

Methods All patients during the study period were offered enrollment in a prospective, randomized study to receive either a titanium, tapered, proximally coated stem; or a Co-Cr, cylindrical, extensively coated stem; 102 patients were enrolled. We collected detailed patient data preoperatively including diagnosis, age, gender, insurance status, medical comorbidities, tobacco and alcohol use, household income, educational level, and history of treatment for lumbar spine pathology. Clinical evaluation included Harris Hip Score, SF-12, WOMAC, pain drawing, and UCLA activity rating and satisfaction questionnaire. Implant factors included stem type, stem size, fit in the canal, and stem-bone stiffness ratios. Minimum 2 year followup was obtained in 95\% of the enrolled patients (102 patients).

Results Patient demographics and preoperative status were more important than implant factors in predicting the presence of thigh pain, dissatisfaction, and a low hip score. The most predictive factors were ethnicity, educational level, poverty level, income, and a low preoperative WOMAC score or preoperative SF-12 mental component score. No implant parameter correlated with outcome or satisfaction.

Conclusion Socioeconomic factors and preoperative status have more impact on the clinical outcome of cementless THA than implant related factors.

Level of Evidence Level I, prospective, randomized clinical trial. See the guidelines online for a complete description of level of evidence.

\section{Introduction}

THA is reliable in achieving long-term component survival of over $95 \%$ at 10 years [4] and high functional scores in a 
very high percentage of cases and has recently been termed "the operation of the century" [30]. Despite its success, a certain percentage [35] of patients experience persistent symptoms, functional limitations, and dissatisfaction following THA. In one recent study, patients expressed some degree of dissatisfaction with some aspect of THA in $40 \%$ of cases [35]. Implant design and surgical technique continue to evolve in an attempt to further improve results. Most THA studies focus on the impact of implant design and/or surgical technique on the standard hip ratings (Harris Hip Score, SF-12, WOMAC, thigh pain incidence, satisfaction scores) following THA [9, 13, 32]. Recent studies have indicated that scores on the Knee Society scoring system, WOMAC, and SF-12 following TKA can be predicted by patient parameters rather than implant or technique factors $[21,28,40]$. A higher incidence of persistent pain and functional limitation reportedly occurs following TKA compared to THA with rates of dissatisfaction in the $10-15 \%$ range [3]. Noble et al. reported functional limitations in up to $40 \%$ of patients following TKA [37]. A number of studies examining suboptimal results following TKA have concluded that patient factors played an important, if not dominant, role in the reported incidence of persistent pain and functional limitation [21, 29].

Relatively little has been written regarding the importance of patient factors on the results of THA [45]. Ritter and McAdoo described the predictors of patients who do not respond well to THA [39]. Among men, preoperative patient factors including less education, more preoperative pain, and lower preoperative ambulatory status were predictive of a poor response. Among women, poor responders to surgery had more preoperative anxiety and physical symptoms, depression, and difficulty relating to people. Young et al. [45] performed an extensive metaanalysis of the THA literature in an attempt to elucidate the effect of patient characteristics on clinical outcomes, defined as activity limitation and prosthesis survival. They concluded, "Although socioeconomic status, educational level, and ethnicity may have an impact on health, the effect of these factors on THA is largely unknown" [45].

We therefore determined the relative importance of implant factors (stem type, size, and fit), preoperative factors, and socioeconomic factors on commonly utilized outcome measures.

\section{Patients and Methods}

We approached all 159 patients meeting our criteria who were scheduled to undergo primary THA from January 2000 through December 2003. One-hundred eight of 115 eligible patients agreed to participate in a prospectively randomized trial using one of two stem designs: a fully coated Co-Cr cylindrical stem (Prodigy, DePuy, Warsaw, IN), and a proximally coated tapered titanium stem (Synergy, Smith \& Nephew, Memphis, TN) (Fig. 1). A number of studies have reported high functional scores with both of these designs $[7,14,18,24,32,38]$ which were the two cementless components with which the authors had clinical experience, thus minimizing the concern for learning curve with the process of stem insertion. We considered patients who were over 18 years old and considered candidates for cementless primary THA. We excluded patients with hip surgery on the affected side, type $\mathrm{C}$ bone not amenable to cementless fixation, preexisting metabolic bone disease, such as Paget's disease or renal osteodystrophy, sickle cell disease, femurs that templated to a stem size greater than $18 \mathrm{~mm}$, inability to appear for followup visits for at least two years, and the presence of an orthopaedic or medical condition that substantially limited ambulation, thus making postoperative hip rating difficult. One hundred and eight patients (119 hips) were enrolled in the study. Of the 11 patients with bilateral total hips, six were performed simultaneously and five at different operations. Only the first hip was randomized and included in the statistical analysis. Participation in this study was voluntary. All patients were provided with an explanation of the study and an opportunity to ask questions. They were assured that nonparticipation or withdrawal would not jeopardize their care. The study protocol, including the consent forms, was approved by the medical school institutional review board. A detailed informed-consent form was signed by each patient, and all information was kept confidential. The patients agreed to be blinded with regard to which procedure they underwent in order to reduce bias in their responses on the followup questionnaires. Randomization was accomplished with use of a randomly selected envelope, which was opened the day before surgery to allow the proper equipment and implants to be ordered.

There were 55 patients who had the proximally coated implant and 53 who had the fully coated implant. The average patient age was 52.7 years (range 23-79 years). There were 35 women (32\%) and 53 African Americans $(49 \%)$. The primary diagnosis was osteoarthritis in 54 $(50 \%)$, avascular necrosis in $49(45 \%)$, and posttraumatic arthritis in five (5\%). One patient was deceased, two were medically incapacitated for reasons unrelated to their hip conditions, and three were lost to followup. Minimum two year followup was thus obtained in 102 of 108 patients (95\%) (mean: 3.2 years; range: 2 to 5 years) (Fig. 1). We performed a post hoc sample size calculation to determine the number of patients who would require pain drawings to detect a substantial difference in the incidence in thigh pain between the two stem types, which was a crucial outcome measure for the study. A previously published study using 
Fig. 1 The CONSORT flowchart is shown.

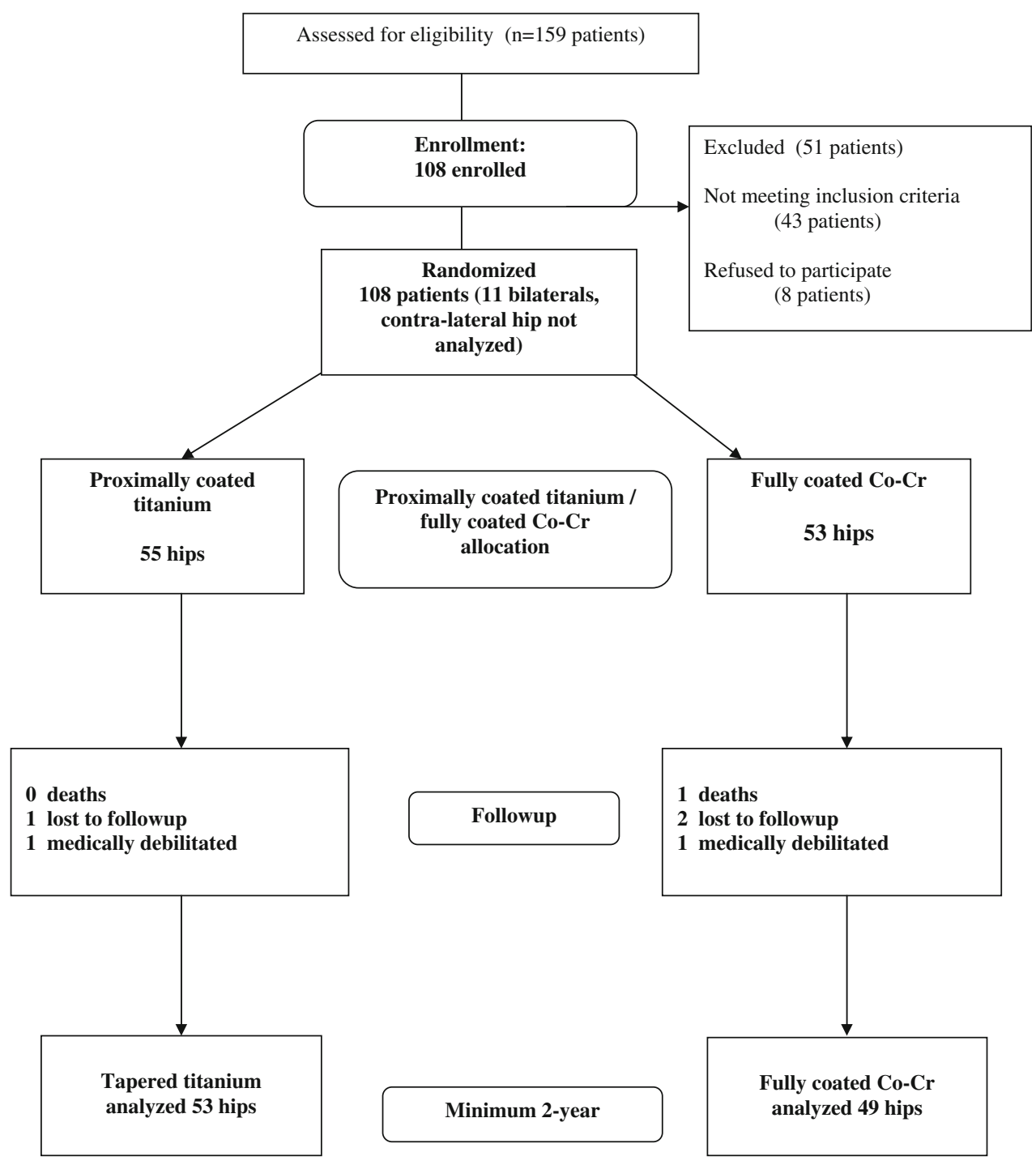

the same methodology reported an incidence of any thigh pain for proximally coated cementless stems of $42 \%$ compared to $19 \%$ for a fully coated stem [5]. Assuming an overall alpha error of $5 \%$ and a statistical power of 0.80 , approximately 124 patients were needed based on the incidences of thigh pain reported in the previous study utilizing similar methodology [5].

Demographic and social information including gender, race, education completed, enrollment in government subsidy programs, disability status, workers compensation claims, annual household income, and number of family members in the household was recorded. Family size and household income were utilized to determine if the individual met the U.S. Department of Health and Human Services Poverty Guidelines as published annually in the Federal Register [20]. Current and previous smoking was documented in pack-years, and if not currently smoking the date of cessation was recorded. Alcohol consumption, prescription narcotic use, and illicit drug use were also documented.

We obtained a complete medical and surgical history including preoperative diagnosis, height, weight, body mass index (BMI), medical comorbidities, previous surgeries, current and previous medications, and familial diseases.

We documented the incidence and severity of patients' pain utilizing a previously described pain drawing [5] as well as a visual analog pain scale (VAS) (Fig. 2). Only pain localized to the middle portion of the front or side view drawing was classified as thigh pain. The incidence and severity of current or previous low back pain and history of treatment for low back pain were also documented.

All cases were performed or supervised by a single surgeon (RLB). A standard posterolateral approach was utilized. The incision was centered over the midshaft of the 
E $\square$

23435

\section{Pain Drawing and Scales}

1. What was the date of $y$ our hip sepiacement surgery $\alpha$, if you have sot had your surgey yet, when will the surgery be done?

2. If you arrently have andy hip or leg pain, where is the location of the pain?
O Thigh Oside of Hip
OButtock ODiffuse
OGroin Oother

3. For the leg in which you had (or are going to have) your hip replacement done, please identify any area(s) where you are experiencing pain by placing a number in the box next to the area(s). Use the scale below to identify your level of pain.

I - Pain with extreme activity only (running excessive walking, etc.)

2 - Pain with moderate activity or specitic movements only (getring in or out of a chair or car, going up or down stairs)

3 - Pain with daily activities (bathing, getting dressed, going to bathroom, etc.)

4 - Pain at rest during the day

5 - Pain at night that wakes you up II have no leg or hip pain
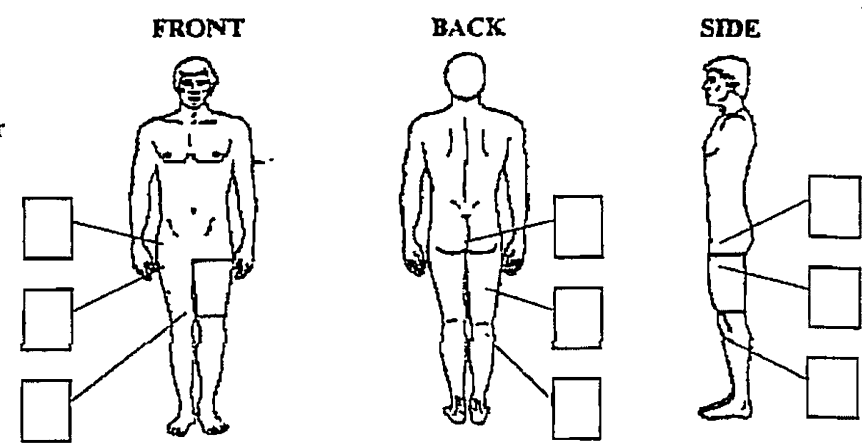

5. The thigh is the portion of the extremity between the lines on the figure. Do you have thigh pain? If yes, please put a mark on the following line: yos, plase Thitgh Savere pain 0 gats

6. Based on a scale of $0-10$ with 0 being no pain and 10 being the worst pain you have ever experiendest in your life, please write down the number that best represents the worst leg pain that you currently experience:

7. Do you currently have low back pain? $\square$ Yes $\square$ No If yes, are you being treated for it? $\square$ Yes $\square$ No

8. Have you bad prior treament for low back pain? $\square$ Yes $\square$ No

9. Have you had prior low back surgery? $\square$ Yes $\square$ No

10. Did you have back pain prior to your hip replacement? $\square$ Yes $\square$ No If yes, has it improved since surgery? $\square$ Yes $\square$ No

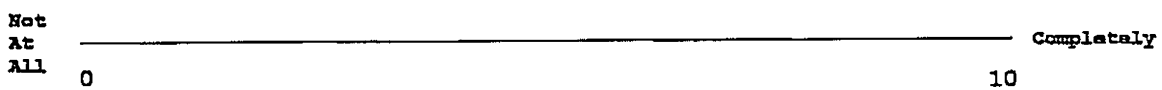

For Office Use Only

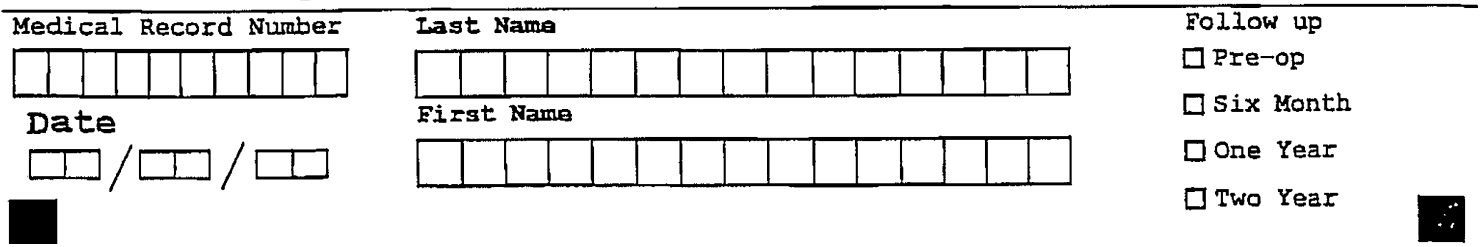

Fig. 2 Pain drawing and questionnaire utilized to assess the presence and severity of hip, thigh, and back pain.

femur distally, extended to the tip of the trochanter, and then curved posteriorly at a $45^{\circ}$ angle. The iliotibial band was incised in the midline and carried through the gluteus maximus fascia proximally. The bursa was incised and the internal rotators including the quadratus femoris was released from the femur. The posterior capsule was also released in a separate layer, tagged with \#5 Ethibond suture creating a rectangular flap. A femoral posterior capsular repair at the edge of the abductor tendon was performed as described by Dixon et al. [15].

The Co-Cr stem was longer $(\mathrm{p}=.008)$ than the tapered titanium stem (172 mm versus $157 \mathrm{~mm}$ ) on average. The 
stem diameter was greater $(p=.02)$ at the level at which both stem diameters matched their stated diameter for the Co-Cr stem $(14.7 \mathrm{~mm}$ versus $13.4 \mathrm{~mm})$, which was an average of $95 \mathrm{~mm}$ from the proximal medial porous coating on average. We recorded the total operative time, blood loss, and component stem type and size. Patients were allowed full weight bearing as tolerated with crutches or a walker (at the therapist's discretion) on the day following surgery. In-home supervised therapy was ordered on discharge with an additional four weeks of outpatient therapy added at the discretion of the therapist until the patient was deemed safe for independent ambulation. Posterior hip precautions were maintained for three months. Low dose Coumadin (target INR 1.5-2.0) for 3 weeks was the standard DVT prophylaxis.

Patients completed functional and quality of life instruments preoperatively and at minimum 2 year followup that included a Harris Hip Score [23], UCLA activity level [2], WOMAC score [6], SF-12 [44], and satisfaction survey [8] with the help of a study coordinator. Both the patient and the coordinator were blinded to stem type through the final followup interval. Clinical data were therefore collected in a double-blind manner and occurrence of any perioperative complications was documented. Routine followup was obtained at 6 weeks, 6 months, one year, and at minimum of 2 years (range 2-5). Forms were completed preoperatively and at minimum 2 year followup.

An AP radiograph of the pelvis was obtained with $15^{\circ}$ of internal rotation preoperatively, postoperatively, and at minimum 2 year followup. A single research assistant (GC) experienced in digital imaging, not involved with the surgical procedures, reviewed the most recent postoperative radiographs for evidence of bone ingrowth, stem subsidence, osteolysis, hypertrophy, bead shedding, and stem fit and fill. Stem fit was quantified by measuring the ratio of the stem width on the AP radiograph to the inner cortical dimension at multiple points as described by Wan et al. [43] (Fig. 3). For the Co-Cr stems, ingrowth was defined according to the criteria described by Engh et al. [18]. For the tapered stems ingrowth was defined by lack of subsidence and absence of lucent lines at the bone implant interface. Stem subsidence was measured by comparing the distance from the interischial line to the top of the lesser trochanter on the early postoperative radiograph compared to the most recent radiograph with a threshold of $>2 \mathrm{~mm}$. Hypertrophy was measured by comparing the cortical thickness at the thickest area near the stem tip between the immediate postoperative and most recent radiograph again with a threshold difference of $>2 \mathrm{~mm}$. All measurements were made utilizing computer digitization software (Imagika, CMC, New Jersey).

The stem-bone stiffness ratio was determined for each patient as described by Wan et al. [43] (Fig. 3). The femoral stiffness was calculated for the femur by measuring the inner and outer cortical diameters at several points at the mid and distal portion of the stem on the AP and lateral radiographs (Fig. 4), assuming an elastic modulus of $17 \mathrm{GPa}$ for cortical bone and a cylindrical geometry for the diaphyseal portion of the femur [43]. The stem modulus and stiffness for each stem size was provided by the manufacturer. The stiffness ratio was defined as the stem stiffness divided by the bone stiffness [43]. The axial, bending, and torsional ratios were calculated as described previously [16, 43]. Intraobserver and interobserver error were not considered in this study and have not been established to the author's knowledge for these measurements.
Fig. 3 Drawing showing how the stem fit and fill was quantified at the proximal, mid, and distal position of the stem. (Adapted from Wan Z, Dorr LD, Woodsome T, Ranawat A, Song M. Effect of stem stiffness and bone stiffness on bone remodeling in cemented total hip replacement. J Arthroplasty. 1999;14(2):149-158 with permission from Elsevier.)

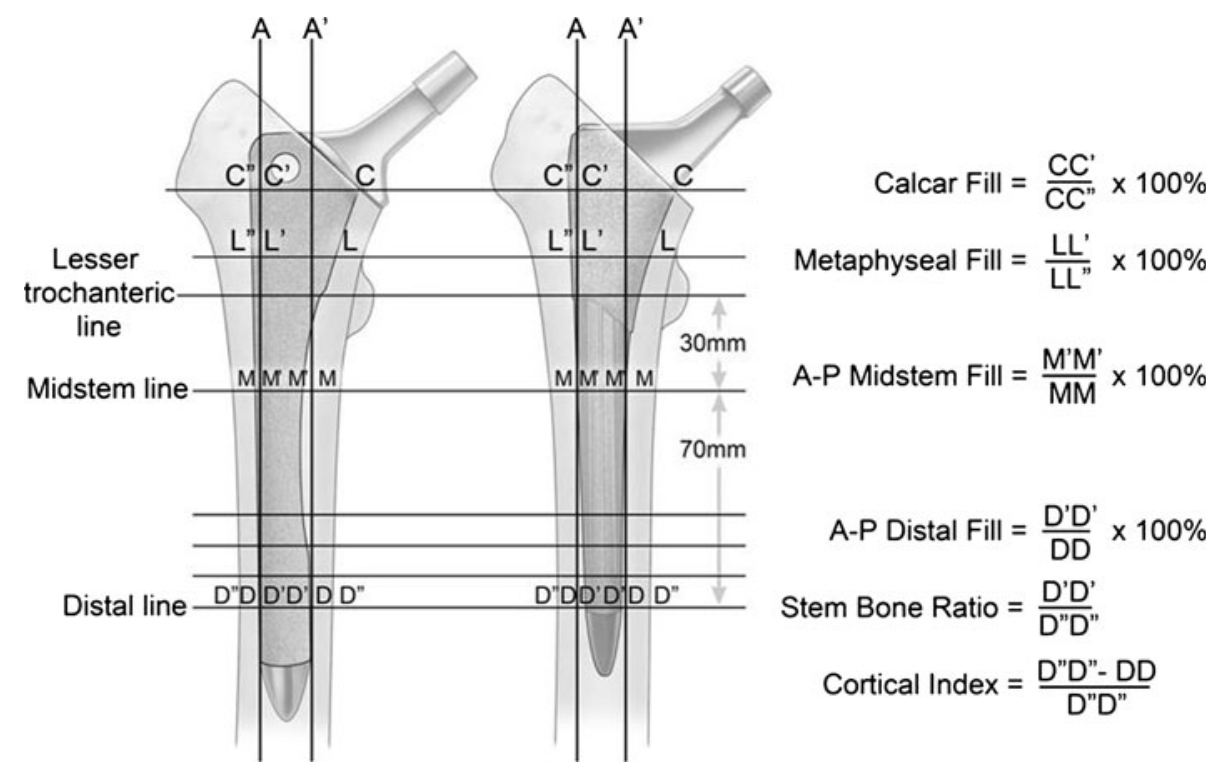


Fig. 4 Drawing showing how the stiffness ratios were calculated by comparing the calculated femoral cortical stiffness based on the dimensions of the femur measured on AP and lateral radiographs compared to the reported implant stiffness for each stem size. (Adapted from Wan Z, Dorr LD, Woodsome T, Ranawat A, Song M. Effect of stem stiffness and bone stiffness on bone remodeling in cemented total hip replacement. $J$ Arthroplasty. 1999;14(2):149-158 with permission from Elsevier.)
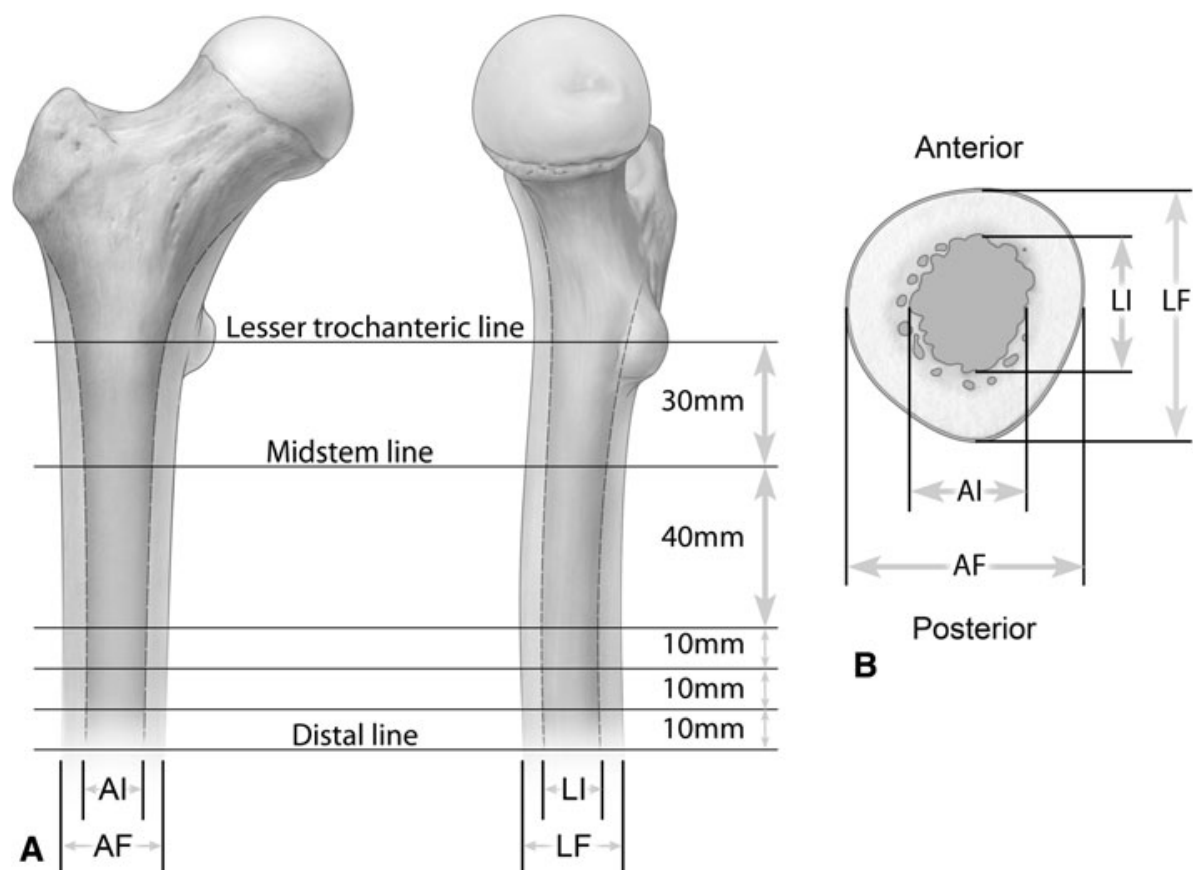

Descriptive statistics (means, frequencies, medians, and percentiles) were used to summarize the data. We determined differences in socioeconomic factors (education, ethnicity, income), patient preoperative status (WOMAC, SF-12), and patient specific characteristics (BMI, smoking, etc.) between the two stem types (Synergy versus Prodigy). In addition to comparing the two stem types, comparisons were performed based on the presence of pain versus no pain, the presence or absence of thigh pain, the presence of thigh pain $\geq 3$ on the VAS, and the presence and degree of satisfaction. Patients classified their degree of satisfaction on a 5 point scale, similar to the rating described by Likert as well as Mahomed et al. [31, 34]. The incidence of those classified as either extremely or very satisfied was compared to those classified as less than very satisfied $[8,31$, 34]. An excellent result on the Harris Hip Score ( $\geq 90)$ compared to a less than excellent result $(<90)$; the presence of a good or excellent Harris Hip Score $(\geq 80)$; compared to a fair or poor result $(<80)$ as described by Harris in his original article describing the Harris Hip Score [23]. Data from the baseline visit and the last followup visit were used for each patient. Differences between groups were assessed using the Wilcoxon twosample test for continuous data and Pearson's chi-square test for categorical data. Fisher's exact test was used when sample sizes were too small to support the Pearson test. Unadjusted odds ratios and $95 \%$ confidence intervals were also computed for categorical data. Given a sufficient sample size, all variables with an unadjusted association with the outcome under study at $(\mathrm{p}<0.20)$ were included as possible predictors in a forward stepwise logistic regression model. Adjusted odds ratios and 95\% confidence intervals were computed for those models. The adjusted odds ratios were consistent with the unadjusted odds ratios in all cases.

\section{Results}

We observed no difference in the presence of thigh pain, Harris Hip Score, and patient satisfaction between the two stem types. All stiffness ratios were greater $(p=.001)$ for the cobalt-chrome (Co-Cr) stem, however the stem fit/fill, and stiffness ratios did not correlate with any of the outcome measures.

The patient preoperative status factors associated with a higher incidence of thigh pain and a lower satisfaction score included a preoperative WOMAC score greater than 51 or a preoperative Mental Component Score on the SF-12 of less than 50 (Table 1).

Socioeconomic factors associated with lower outcome scores included race (African American), education (less than high school), and household income (less than poverty level). African Americans were associated with a higher likelihood of a Harris Hip Score of less than 90, the presence of any thigh pain on a pain drawing, and the presence of thigh pain greater than or equal to 3 on the VAS. Patients with less than a high school education had a higher likelihood of a less than excellent Harris Hip Score, a less than good Harris Hip Score, and thigh pain greater than or 
equal to 3 on the Visual Analog Scale. Patients that were in households below the poverty level had a higher likelihood of having a less than good Harris Hip Score or thigh pain greater than or equal to 3 on the Visual Analog Scale (Table 1).

One patient had a hematoma we surgically evacuated; there was no subsequent evidence of infection. There was one dislocation, treated with closed reduction, with no recurrence of instability. One patient had bead separation during implantation with no apparent sequelae and a Harris Hip Score of 94 at 2 years followup. There were no patients with DVT, PE, wound infection, or revision for any reason.

Table 1. Socioeconomic and patient factors associated with lower outcome scores

\begin{tabular}{|c|c|c|}
\hline Outcome measure & $\begin{array}{l}\text { Patient/socioeconomic } \\
\text { parameter }\end{array}$ & $\mathrm{p}$ Value \\
\hline \multirow{4}{*}{$\begin{array}{l}\text { Less than excellent } \\
\text { HHS }(<90)\end{array}$} & Education $<$ high school & .0008 \\
\hline & Race (African American) & .02 \\
\hline & Pre-op MCS on SF-12 $<50$ & .02 \\
\hline & Pre-op WOMAC > 51 & .05 \\
\hline \multirow{4}{*}{$\begin{array}{l}\text { Fair, poor HHS } \\
\quad(<80)\end{array}$} & Education $<$ high school & .0007 \\
\hline & Pre-op WOMAC > 51 & .02 \\
\hline & Pre-op MCS on SF-12 $<50$ & .03 \\
\hline & Household income $<$ poverty level & .03 \\
\hline \multirow{4}{*}{$\begin{array}{l}\text { Any thigh pain } \\
\text { on pain drawing }\end{array}$} & Pre-op MCS on SF-12 $<50$ & .006 \\
\hline & Household income $<$ poverty level & .06 \\
\hline & Pre-op WOMAC > 51 & .06 \\
\hline & Race (African American) & .08 \\
\hline \multirow{5}{*}{$\begin{array}{l}\text { Thigh pain } \geq 3 \\
\text { on VAS }\end{array}$} & Pre-op MCS on SF-12 $<50$ & .01 \\
\hline & Race (African American) & 0.0068 \\
\hline & Household income $<$ poverty level & 0.002 \\
\hline & Education $<$ high school & .06 \\
\hline & $\geq 2$ Medical Comorbidities & .08 \\
\hline \multirow{5}{*}{$\begin{array}{l}\text { Satisfaction less } \\
\text { than very satisfied } \\
\text { (somewhat satisfied } \\
\text { or less) }\end{array}$} & Pre-op WOMAC > 51 & 0.0002 \\
\hline & Pre-op MCS on SF-12 $<50$ & .02 \\
\hline & $\mathrm{BMI}>40$ & .05 \\
\hline & Education $<$ high school & .06 \\
\hline & Smoker & .09 \\
\hline
\end{tabular}

\section{Discussion}

THA is among the most examined surgical interventions in medicine [30]. Historically, studies have focused on the effect of surgical technique and implant designs on clinical results $[5,7,10,13,20,24,30,32,38,40,43]$. This trend focuses on techniques such as minimal incision surgery [9] and image guided surgery [13], as well as design features such as decreased stem stiffness [1] and shorter stems [41]. Less has been written on the impact of patient preoperative status and socioeconomic factors on the measured clinical outcomes following THA. We therefore determined the relative importance of implant factors (stem type, size, and fit) compared to patient factors (patient preoperative scores on standard rating scales and socioeconomic scales) on results of THA as determined by commonly utilized rating scales.

We recognize the limitations of this study. First is the small sample size. With the numerous parameters studied, a much larger sample size would have been desirable. The relatively low volume of uncomplicated primary THAs performed at this center during this time period that met inclusion criteria limited the ability to enroll a large number of subjects in a reasonable time frame. However, we collected detailed patient and demographic data on all patients and the patient demographics were unique. There were high percentages of patients who were African-American and those living below the poverty level, consistent with census bureau statistics for the location of the study [42], but much higher than the national average (Table 2). This presented the unique opportunity to study the influence of these demographic parameters on THA outcomes with a relatively small sample size. Second, the short term followup of the study is an additional weakness as results could change with longer followup. Third, the results could be specific to some degree to the stems utilized. Both stems have been reported to have good clinical result, $[8,24]$ which could minimize associations due to a ceiling affect.

Our data suggest socioeconomic status and patient preoperative factors have considerable influence on function following THA. We observed no influence of implantrelated features (stem type, diameter, fit, or stiffness ratios)

Table 2. Comparative demographics*

\begin{tabular}{|c|c|c|c|c|}
\hline Demographic parameter & Study group & Orleans parish & Louisiana & USA \\
\hline African-American & $49 \%$ & $58.9 \%$ & $31.7 \%$ & $12.8 \%$ \\
\hline Poverty level & $26 \%$ & $27 \%$ & $19.2 \%$ & $12.7 \%$ \\
\hline Education less than high school degree & $22 \%$ & $25.3 \%$ & $25.2 \%$ & $19.6 \%$ \\
\hline
\end{tabular}

Source: U.S. Census Bureau [42].

* Reflective of Local Population, Different From National Averages. 
on any of the clinical assessment instruments utilized. We did find differences in stem length and stiffness ratios, but no correlation between the stiffness ratio and the presence or severity of thigh pain or any other outcome measure. There was a trend for the titanium stem to have a lower incidence of thigh pain $(>3)$ on the VAS $(p=0.11)$ so the effect of stem stiffness on symptoms may warrant further study. Other surgical parameters such as stem size, canal fill, and relative axial, rotational, or bending stiffness compared to the femur did not correlate with any clinical outcome measure.

In contrast to the negligible effect of implant factors on scores on rating scales, numerous patient preoperative and socioeconomic factors influenced the clinical outcome scores. The presence of a low preoperative WOMAC score $(>51)$ was a poor prognostic sign, a finding previously reported by Lavernia et al. [28]. We associated this with a lower postoperative Harris Hip Score, more thigh pain, and lower satisfaction. The presence of a low preoperative mental component score on the SF-12 had similar importance.

Socioeconomic factors that influenced the hip score, thigh pain, and satisfaction included race (African-American), education (less than high school), income (below poverty level), and the presence of two or more medical comorbidities (Table 1). Recent studies have reported differences in African-Americans relating to THA, including increased levels of concern about postoperative pain [26], unwillingness to consider THA [25], lower preoperative functional score and health status [29], and lower expectations of surgical outcomes [22]. A number of parameters were not associated with inferior outcome, including history of narcotic use, smoking, alcohol, and presence of back pain. The diagnosis was a factor as avascular necrosis (AVN) was associated with a higher incidence of postoperative thigh pain, regardless of stem type.

Previous studies of hip and knee scoring instruments among healthy patients reported lower scores among patients living below the poverty level and those with two or more major medical comorbidities, similar to the finding of this study $[10,11]$. In addition, this study also found a strong association between patients' educational level and race and low postoperative outcome scores. For the two commonly utilized implant designs used in this study, implant factors demonstrated no impact on any clinical scores on rating scales, while the patient's preoperative status (WOMAC score and SF-12 mental component score) and socioeconomic factors (race, income, and education) influenced numerous outcome measures. Most studies do not measure these parameters in reporting their results including the vast majority of randomized clinical trials $[12,27,33,36]$. With increased attention to the delivery of health care, including THA, to underserved populations [17, 19], the impact of socioeconomic factors on traditional outcome measures assumes more importance. We found patient and socioeconomic factors were far more important in predicting outcome and satisfaction than implant factors. These factors should be considered when assessing the results of THA studies. Based on these results, the role of socioeconomic factors on patient outcome and satisfaction following THA warrants further study.

Acknowledgment We thank Gerrie Chaisson for her tireless efforts in taking hundreds of measurements of digital images for the radiographic portion of this study.

\section{References}

1. Akhavan S, Matthiesen MM, Schulte L, Penoyar T, Kraay MJ, Rimnac CM, Goldberg VM. Clinical and histologic results related to a low-modulus composite total hip replacement stem. $J$ Bone Joint Surg Am. 2006;88:1308-1314.

2. Amstutz HC, Thomas BJ, Jinnah R, Kim W, Grogan T, Yale C. Treatment of primary osteoarthritis of the hip. A comparison of total joint and surface replacement arthroplasty. J Bone Joint Surg Am. 1984;66:228-241.

3. Baker PN, van der Meulen JH, Lewsey J, Gregg PJ. The role of pain and function in determining patient satisfaction after total knee replacement. Data from the National Joint Registry for England and Wales. J Bone Joint Surg Br. 2007;89:893-900.

4. Barrack RL, Mulroy RD, Jr., Harris WH. Improved cementing techniques and femoral component loosening in young patients with hip arthroplasty. A 12-year radiographic review. $J$ Bone Joint Surg Br. 1992;74:385-389.

5. Barrack RL, Paprosky W, Butler RA, Palafox A, Szuszczewicz E, Myers L. Patients' perception of pain after total hip arthroplasty. J Arthroplasty. 2000;15:590-596.

6. Bellamy N, Buchanan WW, Goldsmith $\mathrm{CH}$, Campbell J, Stitt LW. Validation study of WOMAC: a health status instrument for measuring clinically important patient relevant outcomes to antirheumatic drug therapy in patients with osteoarthritis of the hip or knee. J Rheumatol. 1988;15:1833-1840.

7. Belmont PJ, Jr, Powers CC, Beykirch SE, Hopper RH, Jr, Engh CA, Jr, Engh CA. Results of the anatomic medullary locking total hip arthroplasty at a minimum of twenty years. A concise follow-up of previous reports. J Bone Joint Surg Am. 2008;90:1524-1530.

8. Bourne RB, Chesworth BM, Davis AM, Mahomed NN, Charron KD. Patient satisfaction after total knee arthroplasty: who is satisfied and who is not? Clin Orthop Relat Res.468:57-63.

9. Bozic K. Single mini-incision has some perioperative advantages over standard-incision total hip replacement. J Bone Joint Surg Am. 2009;91:1279.

10. Brinker MR, Lund PJ, Barrack RL. Demographic biases of scoring instruments for the results of total knee arthroplasty. $J$ Bone Joint Surg Am. 1997;79:858-865.

11. Brinker MR, Lund PJ, Cox DD, Barrack RL. Demographic biases found in scoring instruments of total hip arthroplasty. $J$ Arthroplasty. 1996;11:820-830.

12. Burnett RS, Haydon CM, Rorabeck CH, Bourne RB. Patella resurfacing versus nonresurfacing in total knee arthroplasty: results of a randomized controlled clinical trial at a minimum of 10 years' followup. Clin Orthop Relat Res. 2004:12-25.

13. Confalonieri N, Manzotti A, Montironi F, Pullen C. Leg length discrepancy, dislocation rate, and offset in total hip replacement 
using a short modular stem: navigation vs conventional freehand. Orthopedics. 2008;31(10 Suppl 1).

14. Danesh-Clough T, Bourne RB, Rorabeck CH, McCalden R. The mid-term results of a dual offset uncemented stem for total hip arthroplasty. J Arthroplasty. 2007;22:195-203.

15. Dixon MC, Scott RD, Schai PA, Stamos V. A simple capsulorrhaphy in a posterior approach for total hip arthroplasty. J Arthroplasty. 2004;19:373-376.

16. Dujovne AR, Bobyn JD, Krygier JJ, Miller JE, Brooks CE. Mechanical compatibility of noncemented hip prostheses with the human femur. J Arthroplasty. 1993;8:7-22.

17. Dunlop DD, Manheim LM, Song J, Sohn MW, Feinglass JM, Chang HJ, Chang RW. Age and racial/ethnic disparities in arthritis-related hip and knee surgeries. Med Care. 2008;46: 200-208.

18. Engh CA, Massin P, Suthers KE. Roentgenographic assessment of the biologic fixation of porous-surfaced femoral components. Clin Orthop Relat Res. 1990:107-128.

19. Escalante A, Espinosa-Morales R, del Rincon I, Arroyo RA, Older SA. Recipients of hip replacement for arthritis are less likely to be Hispanic, independent of access to health care and socioeconomic status. Arthritis Rheum. 2000;43:390-399.

20. Federal Registry: Federal Poverty Income Guidelines for Fiscal Year 2003. February 7, 2003 ed. Washington, D.C.: Government Printing Office:6456-6458.

21. Franklin PD, Li W, Ayers DC. The Chitranjan Ranawat Award: functional outcome after total knee replacement varies with patient attributes. Clin Orthop Relat Res. 2008;466:2597-2604.

22. Groeneveld PW, Kwoh CK, Mor MK, Appelt CJ, Geng M, Gutierrez JC, Wessel DS, Ibrahim SA. Racial differences in expectations of joint replacement surgery outcomes. Arthritis Rheum. 2008;59:730-737.

23. Harris WH. Traumatic arthritis of the hip after dislocation and acetabular fractures: treatment by mold arthroplasty. An endresult study using a new method of result evaluation. J Bone Joint Surg Am. 1969;51:737-755.

24. Hennessy DW, Callaghan JJ, Liu SS. Second-generation extensively porous-coated THA stems at minimum 10-year followup. Clin Orthop Relat Res. 2009;467:2290-2296.

25. Ibrahim SA, Siminoff LA, Burant CJ, Kwoh CK. Differences in expectations of outcome mediate African American/white patient differences in "willingness" to consider joint replacement. Arthritis Rheum. 2002;46:2429-2435.

26. Ibrahim SA, Siminoff LA, Burant CJ, Kwoh CK. Understanding ethnic differences in the utilization of joint replacement for osteoarthritis: the role of patient-level factors. Med Care. 2002; 40:I44-I51.

27. Laupacis A, Bourne R, Rorabeck C, Feeny D, Tugwell P, Wong C. Comparison of total hip arthroplasty performed with and without cement : a randomized trial. J Bone Joint Surg Am. 2002; 84-A:1823-1828.

28. Lavernia C, D’Apuzzo M, Rossi MD, Lee D. Is postoperative function after hip or knee arthroplasty influenced by preoperative functional levels? J Arthroplasty. 2009;24:1033-1043.
29. Lavernia CJ, Lee D, Sierra RJ, Gomez-Marin O. Race, ethnicity, insurance coverage, and preoperative status of hip and knee surgical patients. J Arthroplasty. 2004;19:978-985.

30. Learmonth ID, Young C, Rorabeck C. The operation of the century: total hip replacement. Lancet. 2007;370:1508-1519.

31. Likert R. A technique for the measurement of attitudes. Arch Psychol. 1932;140:1-55.

32. Lombardi AV, Jr., Berend KR, Mallory TH, Skeels MD, Adams JB. Survivorship of 2000 tapered titanium porous plasma-sprayed femoral components. Clin Orthop Relat Res. 2009;467:146-154.

33. MacDonald SJ, McCalden RW, Chess DG, Bourne RB, Rorabeck $\mathrm{CH}$, Cleland D, Leung F. Metal-on-metal versus polyethylene in hip arthroplasty: a randomized clinical trial. Clin Orthop Relat Res. 2003:282-296.

34. Mahomed N, Sledge C, Daltroy L, Fossel A, Katz J. Selfadministered patient satisfaction scale for joint replacement arthroplasty. J Bone Joint Surg Br. 1998;80(Suppl 1):9.

35. Mancuso CA, Jout J, Salvati EA, Sculco TP. Fulfillment of patients' expectations for total hip arthroplasty. J Bone Joint Surg Am. 2009;91:2073-2078.

36. McCalden RW, MacDonald SJ, Rorabeck CH, Bourne RB, Chess DG, Charron KD. Wear rate of highly cross-linked polyethylene in total hip arthroplasty. A randomized controlled trial. J Bone Joint Surg Am. 2009;91:773-782.

37. Noble PC, Gordon MJ, Weiss JM, Reddix RN, Conditt MA, Mathis KB. Does total knee replacement restore normal knee function? Clin Orthop Relat Res. 2005:157-165.

38. Parvizi J, Keisu KS, Hozack WJ, Sharkey PF, Rothman RH. Primary total hip arthroplasty with an uncemented femoral component: a long-term study of the Taperloc stem. J Arthroplasty. 2004;19:151-156.

39. Ritter MA, McAdoo WG. A method for determining success following total hip replacement surgery. Clin Orthop Relat Res. 1979:44-49.

40. Santaguida PL, Hawker GA, Hudak PL, Glazier R, Mahomed NN, Kreder HJ, Coyte PC, Wright JG. Patient characteristics affecting the prognosis of total hip and knee joint arthroplasty: a systematic review. Can J Surg. 2008;51:428-436.

41. Santori FS, Manili M, Fredella N, Tonci Ottieri M, Santori N. Ultra-short stems with proximal load transfer: Clinical and radiographic results at five-year follow-up. Hip Int. 2006;16 Suppl 3:31-39.

42. U.S. Census Bureau. QuickFacts - Orleans Parish, Louisiana. Retrieved December 29, 2008, from http://quickfacts.census. gov/qfd/states/22/22071.html.

43. Wan Z, Dorr LD, Woodsome T, Ranawat A, Song M. Effect of stem stiffness and bone stiffness on bone remodeling in cemented total hip replacement. J Arthroplasty. 1999;14:149-158.

44. Ware JE J, Kosinski M, Keller SD. SF-12: How to Score the SF-12 Physical and Mental Health Summary Scales, 3rd ed. Lincoln, RI: QualityMetric Incorporated; 1998.

45. Young NL, Cheah D, Waddell JP, Wright JG. Patient characteristics that affect the outcome of total hip arthroplasty: a review. Can J Surg. 1998;41:188-195. 